\title{
NATURAL CONVECTION IN SECONDARY SODIUM CIRCUIT OF FAST BREEDER TEST REACTOR
}

\author{
Vaidyanathan $\mathrm{G}^{1}{ }^{1}$, Kasinathan $\mathrm{N}^{2}{ }^{2}$, Velusamy $\mathrm{K}^{3}$ \\ 1,2,3 Indira Gandhi Centre for Atomic Research, Kalpakkam, India \\ Email ID: ${ }^{1}$ ganesan.vaidyanathan@gmail.com
}

\section{Abstract}

Fast Breeder Test Reactor(FBTR) is in operation since 1985. Tests and analysis have been performed to assess the conduciveness of the layout to natural convection under loss of pumping flow conditions. One such test refers to the secondary sodium circuit, which forms the link between the heat source (Core) in the primary sodium system and the steam generator which is the final heat sink. This paper details out the tests and two one dimensional numerical models for assessing the flow and compares the predictions with actual test results. Though there is a reasonable match, better assessment is possible with multidimensional models to predict the flow stagnation regions.

Key Words: Fast Reactor, Sodium, Intermediate Heat Exchanger, Piping, Natural convection, Test, Numerical model.

Nomenclature: I - Flow Inertia, W - Sodium Flow, $\mathrm{P}$ - Pressure, $\Delta \mathrm{P}$ - Pressure drop, $\mathrm{P}$ - Density of Sodium, $\mathrm{A}$ - Cross Section Area of sodium Tanks, $L$ - Sodium Level, $\Delta Z$ - Elevation difference of a pipe/component segment

Subscripts: 1 Pipe from Surge tank to pump tank through SG, 2 Pipe from pump tank to surge tank through IHX, st,pt Surge Tank, pump tank, f,g Friction, potential drops

\section{INTRODUCTION}

Fast Breeder Test Reactor (FBTR) is a $40 \mathrm{MWt}$, 13.2 MWe liquid sodium cooled fast reactor, in operation, since 1985. Fig.1 shows a schematic of FBTR plant. The heat produced due to fission in the core is transported to an intermediate heat exchanger
(IHX) by the primary sodium. Secondary sodium picks up the heat from the primary sodium in $\mathrm{IHX}$ and transfers the heat to water/steam in a steam generator (SG). The steam produced in $S G$ is used to drive a turbine generator. In any nuclear reactor, fission products produced in fission continue to decay

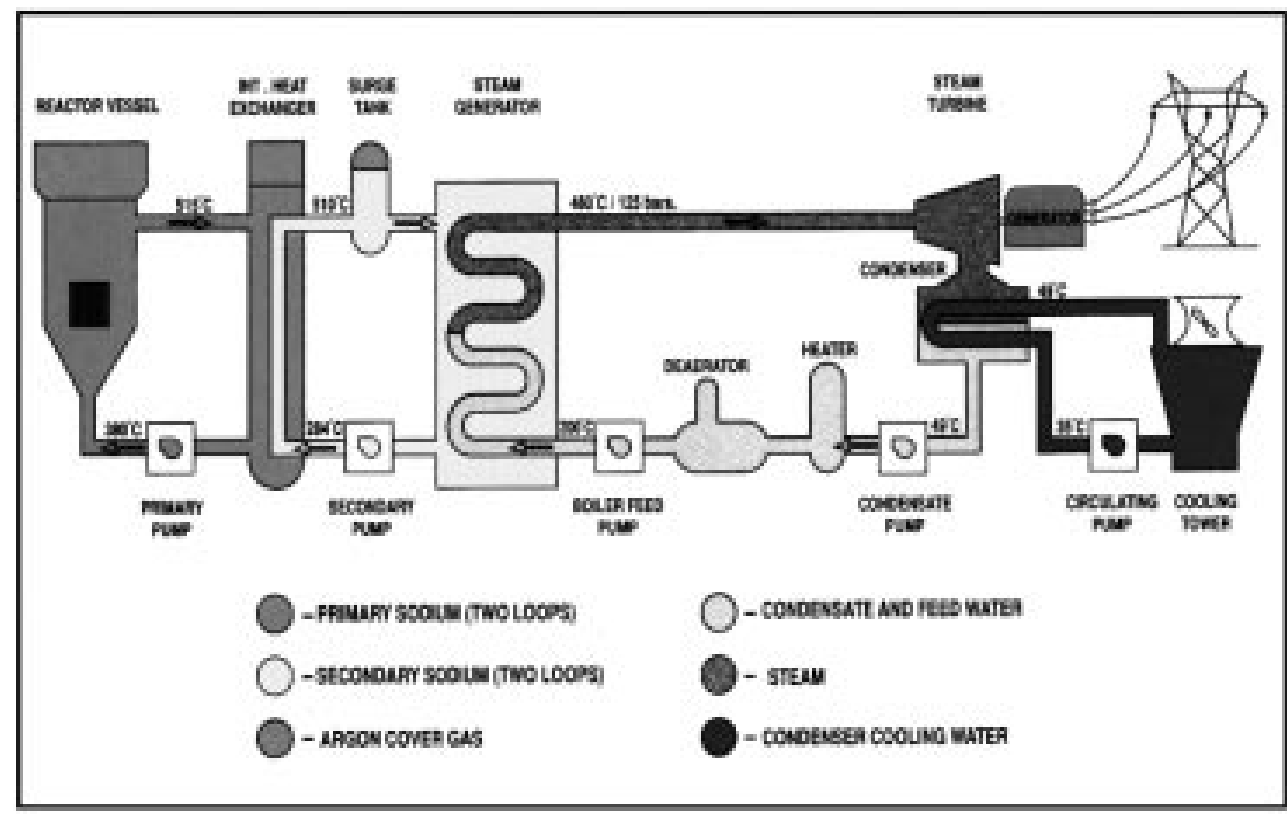

Fig. 1. Schematic-Fast Breeder Test Reactor, India. 
producing about $5 \%$ of the total heat and this referred to as decay heat. After a reactor trip this decay heat comes down with time, as production of new fission products has stopped. This decay heat is necessary to be removed from the reactor core even after shutdown to keep the temperatures of fuel clad within limits. When the power supply is available, the primary pumps and secondary pumps would remove the decay heat through the SG as in normal operation. In case of power failure and non availability of emergency power, the SG casing trap doors are opened, to allow entry of air to flow over the bare surfaces of the SG to remove the decay heat. The transport of heat from the reactor to $\mathrm{IHX}$ and $\mathrm{IHX}$ to $S G$ would be through flow of primary and secondary sodium under natural convection. To ensure adequate natural convection the elevations of IHX and SG with reference to core and the hydraulic resistance of core, primary and secondary piping have to be suitably engineered.

Experimentally, the best way would be to carry out a simulation of complete loss of offsite and onsite power from the full power conditions. However experiments in all reactors to date, have been carried out at low power levels, by tripping the power sources followed by SCRAM or at low steady state power without SCRAM after tripping of the pumps. The steady power is taken to be representative of the decay heat. In these experiments the control rods are adjusted to counteract the reactivity feedbacks due to primarily, the thermal expansion of the core. Such experiments would therefore be useful in ascertaining the reactivity feedback effects, which can be used by the numerical simulation tools to predict for higher powers.

Under natural convection conditions, the sodium flow, the buoyancy heads and temperatures are closely linked to each other. Any uncertainty in one would affect other parameters. Tests under natural convection at low powers corresponding to decay power levels have been reported for PHENIX and SUPER PHENIX reactors in France, PFR in UK, EBR-II in USA, and JOYO in Japan (1-5). It is heartening to note that for two reactors. Viz. RAPSODIE in France and EBR II in USA, tests were carried out at half the full power in RAPSODIE and full power in EBR II, with loss of offsite and onsite power and without reactor trip $(6,7)$. In both cases the reactor power came down gradually due to the negative feedback effects. The power and sodium flow evolution for RAPSODIE is indicated in Fig.2.

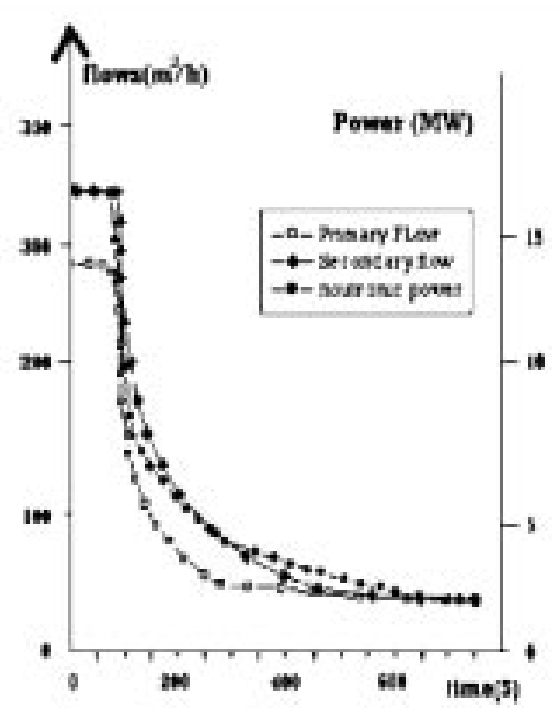

Fig. 2. Evolution of power and sodium flow in

\section{RAPSODIE}

For FBTR, tests at decay power levels have first been done for the primary and secondary circuits separately to assess the individual natural convection flow development. Here the reactor is operated at a low power ( 100-200KW) and the primary pumps alone are tripped and the evolution of the primary flow observed. In a similar way for the same low power, the secondary pumps alone are tripped to assess the natural convection flow evolution. Afterwards both the set of pumps are tripped as an integral test.

The prediction of the flows has been carried out by means of one dimensional model. Details of models used for different reactors are not available in open literature. A computer code DYNAM has been earlier developed for the study of the transient simulation of FBTR (8). This code is one dimensional, and has thermal and hydraulic models of core, primary sodium circuit, IHX, Secondary sodium and steam generator. The Secondary sodium circuit, comprising the SG, surge tank, expansion tank and IHX has been modeled as a single unit for hydraulic resistance. This paper focuses attention on the tests conducted in FBTR for evaluating natural convection flow in the secondary sodium circuit and compares the measurements with the predictions of DYNAM. It also presents the predictions of an improved model of the secondary sodium circuit incorporated in the DYNAM code has led to closer match with the predictions. 
Vaidyanathan et al : Natural Convection in Secondary Sodium...

\section{CIRCUIT DESCRIPTION}

There are two secondary circuits in FBTR, with each served by an IHX linked to two serpentine SGs, a centrifugal pump housed in an expansion tank in the cold leg and a surge tank between IHX and SG in the hot leg. Argon is used as the inert gas cover at the free level of sodium in the expansion and surge tanks. The IHX (Fig.3) is a vertical shell and tube countercurrent heat exchanger. Primary sodium flows from top to bottom on the shell side and secondary sodium flows from bottom to top inside the tubes, after flowing down through a central downcomer.

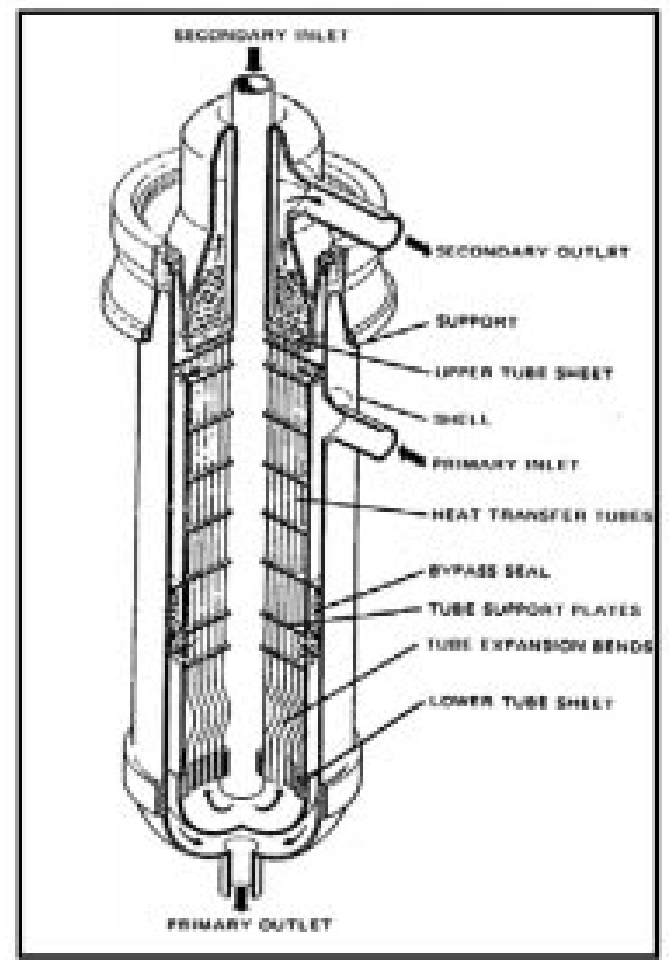

Fig. 3. IHX of Fast Reactor

The interconnecting pipelines and vessels are insulated with SPINTEX insulation material. The four

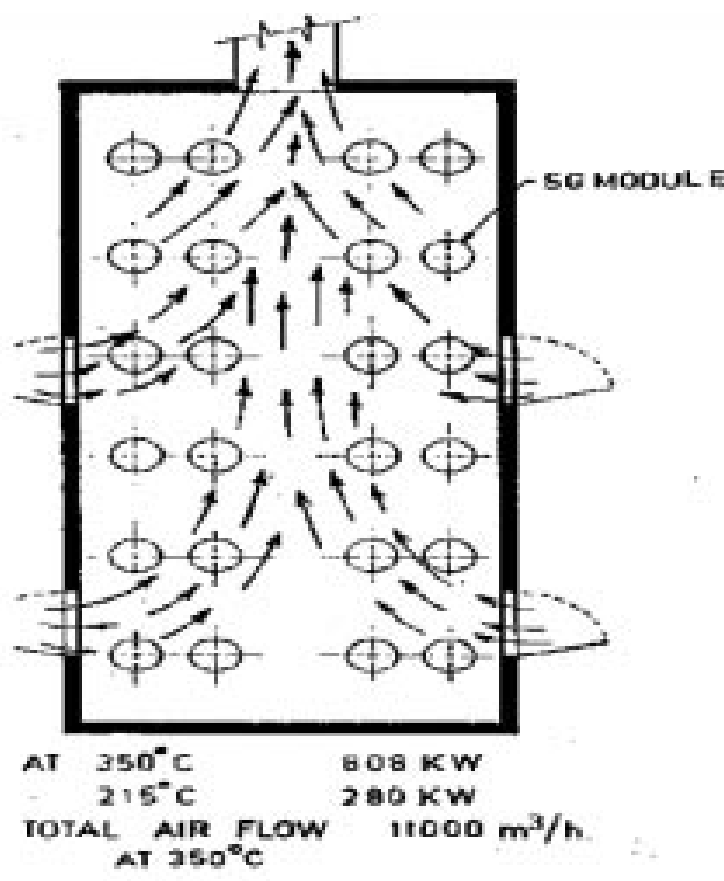

Fig. 4. FBTR SG Modules in Casing

modules of SG (two per secondary loop) are all enclosed in a single insulated casing as shown in Fig. 4 The casing is provided with a system of trap doors and outlet louvers, which when opened will allow natural convection flow of air over the bare surfaces of $S G$ shell and inside casing surface. However during the tests on secondary circuit tests the trap doors were not opened as the operating power was $180 \mathrm{KW}$ compared to $574 \mathrm{KW}$ heat removal capacity with trap doors open. Tests were earlier done at different isothermal temperature conditions to assess the actual heat losses in the different parts of the secondary circuit viz. heat losses from the SG casing with closed louvers, heat loss from piping surfaces in the primary and secondary sodium systems.Table 1 shows the measured heat losses.

Table I. SUMARY OF HEAT LOSS DATA OBTAINED FROM THE PLANT MEASUREMENTS.

\begin{tabular}{|c|l|c|c|c|c|c|}
\hline Serial No. & \multicolumn{1}{|c|}{ Isothermal sodium temperature (deg C) } & $\mathbf{2 0 0}$ & $\mathbf{2 5 0}$ & $\mathbf{3 0 0}$ & $\mathbf{3 5 0}$ & $\mathbf{4 0 0}$ \\
\hline 1 & Total system heat loss (kw) & 170 & 240 & 313 & 413 & 574 \\
\hline 2 & Heat loss form the SG casing alone(kw) & 47 & 75 & 107 & 144 & 186 \\
\hline 3 & Heat loss from pipeline surfaces alone (kw) (1-2) & 123 & 165 & 206 & 269 & 388 \\
\hline 4 & Heat loss from primary sodium pipe sureface (kw) & 45 & 60 & 74 & 97 & 139 \\
\hline 5 & Heat loss from secondary sodium pipe surfaces (kw) & 78 & 105 & 132 & 172 & 249 \\
\hline
\end{tabular}




\section{PROCESS MODEL}

To predict the evolution of temperatures and flows during establishment of natural convection an one dimensional code DYNAM has been developed (8). The important features of the model are enumerated in the following lines. The core heat generation as a function of the total reactivity is calculated using the point kinetics approach. The thermal model comprises the different subassemblies namely, fissile, blanket, reflector and shielding, each being represented by an average subassembly. The hot pool is represented by a mixing region in contact with a stagnant zone above the reactor outlet pipes (Fig.5). IHX thermal model considers a lumped parameter single tube representation. Heat transfer coefficients from sodium to ambient in vessels, piping etc. are calculated based on the measured heat losses. For flow estimation one dimensional momentum balance equation is used. In the model for secondary sodium circuit, the effect of accumulation or depletion of sodium in the expansion and surge tanks is not considered. In other words, the level changes in sodium and their effect on the flow is neglected. The buoyancy term is obtained by summing up the buoyancy forces in the different segments based on the temperatures' given by the thermal model. More details on the details of model and numerical solution techniques adopted are reported elsewhere (8).

\section{ANALYSIS OF A NATURAL CIRCULATION LOOP}

Studies have been reported in connection with the natural convection decay heat removal of the KALIMER reactor under design in Korea (9). As a first

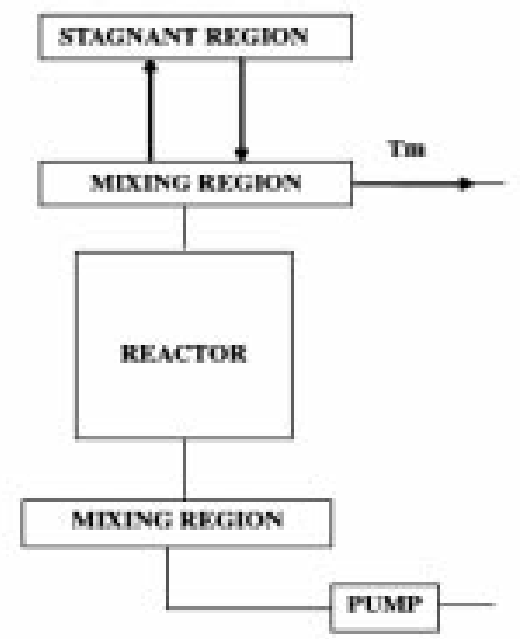

Fig. 5. Hot and Cold Pool Model

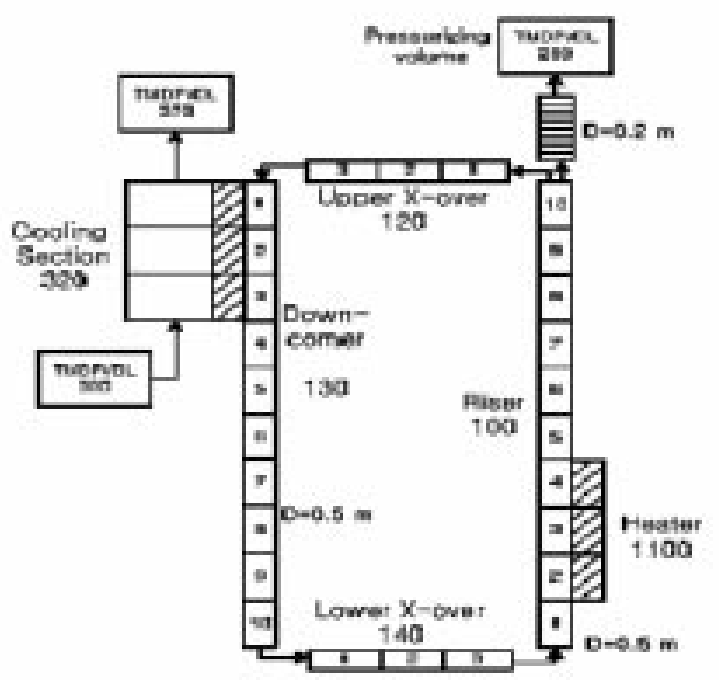

Fig. 6. Schematics of sodium loop for the numerical test

part of the numerical study, a simple closed sodium circulation loop is simulated for the evaluation of the formation and effectiveness of natural circulation in a liquid metal loop. The schematic of the numerical test loop is depicted in Fig.6. The total height of riser part is $10 \mathrm{~m}$ and the same height is assumed for down comer passing through the cooling part. Initially, stagnant liquid sodium at $200^{\circ} \mathrm{C}$ is filled in the circulating pipes of $50 \mathrm{~cm}$ in diameter. To investigate the formation of a stable natural circulation flow in the loop, the heat is applied via the heater and extracted via the cooler. The heat rate applied to the heater is increased from $100 \mathrm{~kW}$ to $300 \mathrm{~kW}$ for equilibrium between the heating rate and the cooling rate. Natural circulation flow rate and temperature in the loop for the power of $300 \mathrm{~kW}$ is discussed below.

Figs. 7 and 8 show the formation and a change of natural circulation flow rate when the heater power

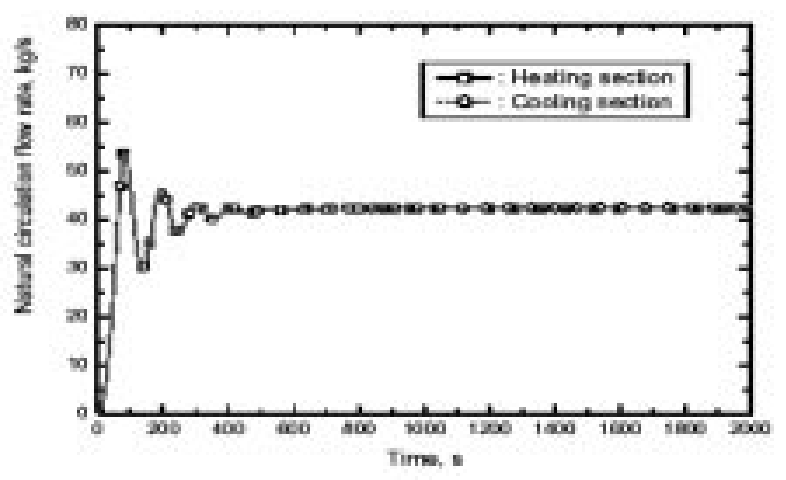

Fig. 7. Evolution of Natural circulation flow (MARS) 


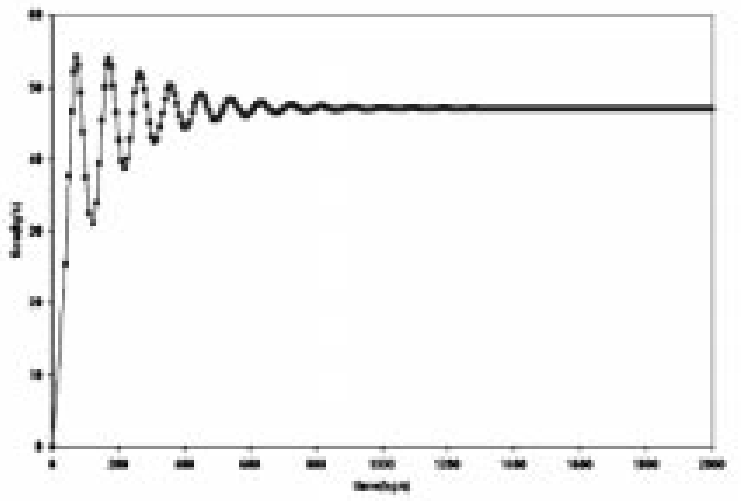

Fig. 8. Evolution of Natural circulation flow (DYNAM)

is $300 \mathrm{~W}$ as predicted by the Korean analysis (MARS code)and the analysis with DYNAM model incorporating a single flow model respectively. It is notable that an oscillatory motion in the flow rate is found at an early stage of the transient. The difference in value between analysis by MARS and present analysis may be due to the different correlations used for friction factor including roughness calculations. This has been checked by varying the friction factor and flow was found to be sensitive to the same. This shows that the hydraulic resistance determination is very crucial for natural convection predictions.

\section{FBTR TEST DESCRIPTION}

The reactor was stabilized at a power of $180 \mathrm{KW}$. This power corresponds to the decay power of the reactor $5 \mathrm{~min}$. after a reactor shutdown. The test was initiated by tripping the two secondary pumps simultaneously. The secondary flow coasted down under the drive system inertia. When the pump speed reached $200 \mathrm{rpm}$, the pump was brought to zero speed

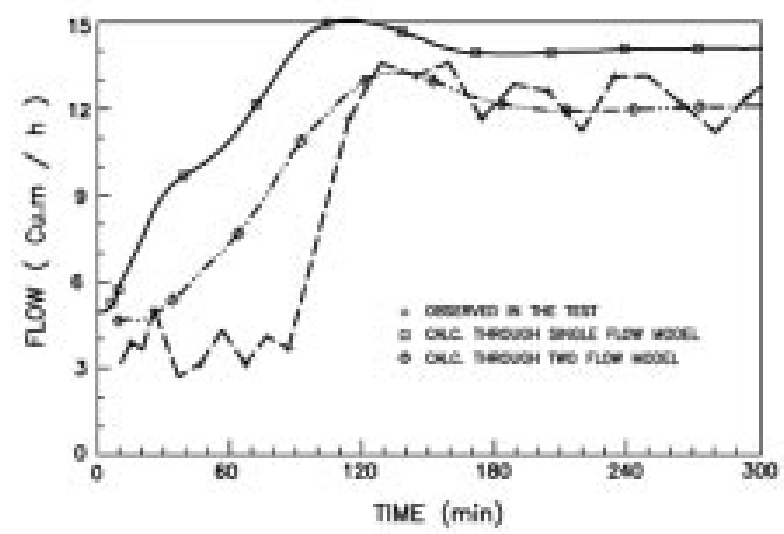

Fig. 9. Evolution of Secondary sodium flow-Test \& Predictions rapidly to protect the hydrostatic bearings. The flow fell down from 130 to $80 \mathrm{Cu} . \mathrm{m} / \mathrm{h}$ in $5 \mathrm{~min}$. and further fell down to natural convection levels. The pumps stopped completely in $7 \mathrm{~min}$., when the flow rate was $\sim 5$ Cu.m $/ \mathrm{h}$. The flow evolution subsequent to this is given in Fig.9. It also shows the evolution of reactor power and sodium flows during the test and predictions. The natural convection flow stagnates around $4 \mathrm{Cu} . \mathrm{m} / \mathrm{h}$ from 10 to $90 \mathrm{~min}$. and then rises gradually to a maximum value of $13.5 \mathrm{Cu} . \mathrm{m} / \mathrm{h}$ in the next $40 \mathrm{~min}$. and then fluctuates between 11 and 13 cu.m/h for next $2.5 \mathrm{~h}$. However the flow shows oscillations, which are periodic, in the first $90 \mathrm{~min}$. The reactor power remains nearly constant at $180 \mathrm{KW}$ for about $8 \mathrm{~min}$. and then falls, as a consequence of rise in reactor inlet temperature, which brings in negative reactivity contribution. The power reaches a low value of $35 \mathrm{KW}$ at $45 \mathrm{~min}$. (Fig.10)and then remains constant for next

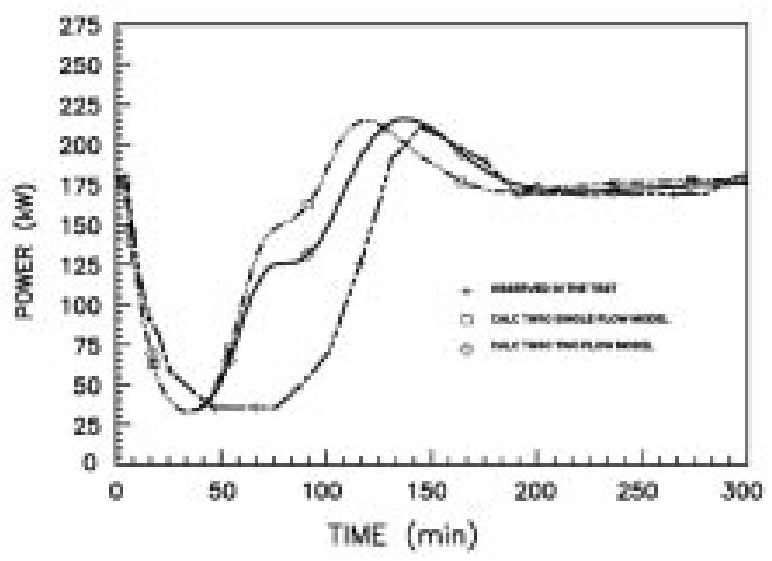

Fig. 10. Evolution of Reactor Power-Test \& Predictions

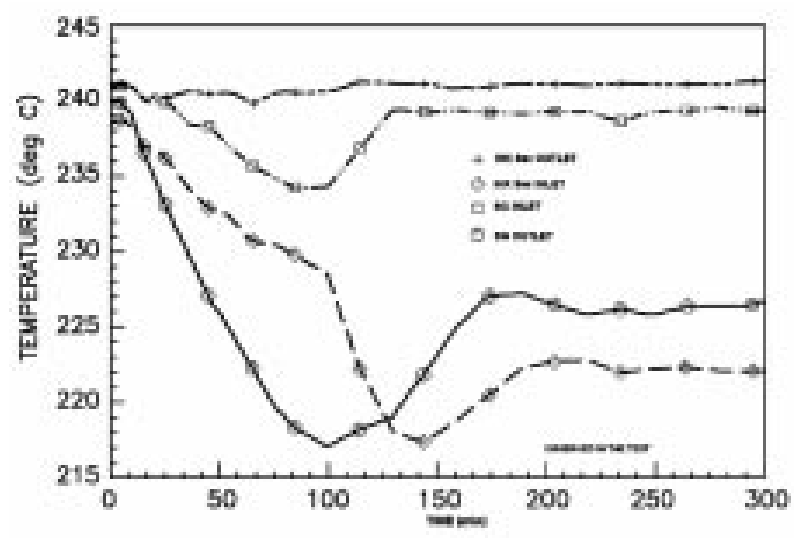

Fig. 11. Evolution of IHX and SG Temperatures-TEST 
45 min. afterwards the power rises to a maximum of $210 \mathrm{KW}$ at $142 \mathrm{~min}$ and drops to $170 \mathrm{KW}$ at $190 \mathrm{~min}$. The power fluctuations are governed by the reactivity changes as a consequence of temperature changes in the core. The evolution of IHX and SG sodium temperatures in the secondary sodium circuit are shown in Fig.11.

\section{DYNAM PREDICTIONS}

Predictions of the secondary natural convection flows using DYNAM computer code for the test is indicated in the Fig. 9. Since the secondary sodium flow is same throughout the circuit in this model, it is referred to as single flow model. It can be seen that the natural convection flow predicted by this model increases right from beginning. From a value of 5 Cu.m/h it rises, without any stagnation unlike in the test where it stagnates at $4 \mathrm{Cu} . \mathrm{m} / \mathrm{h}$ for $80 \mathrm{~min}$. Though final predicted steady state flow is fairly comparable to that observed in the tests, it is clear that the transient evolution is affected by cyclic effects which can be attributed to level changes in the two capacities viz. expansion and surge tanks.. The model is also not able to capture the initial flow oscillations. The evolution of reactor power and $\mathrm{IHX}$ and SG temperatures is indicated in Fig. 12 , which also shows deviation from the test results.

\section{TWO FLOW MODEL}

The single flow model employed in the DYNAM code was therefore modified by considering the sodium flow in the pipe from IHX to Surge tank and from surge tank to expansion tank separately, along with the level

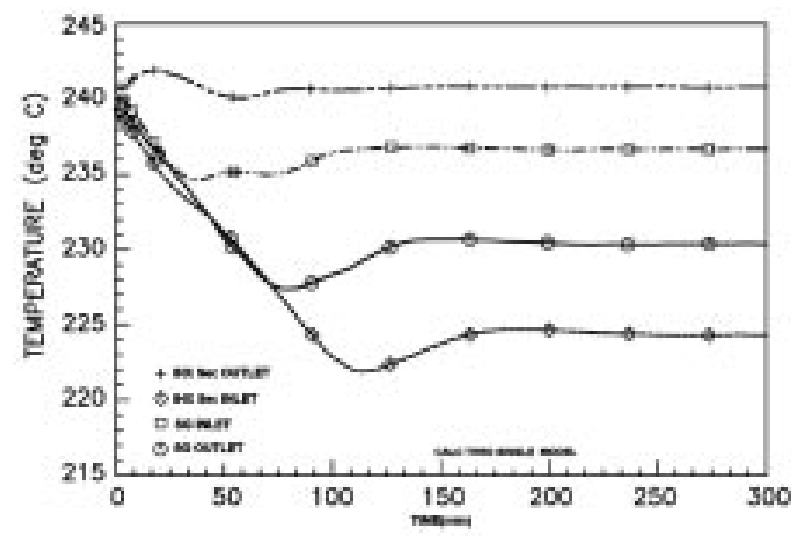

Fig. 12. Evolution of $I H X$ and $S G$ Temperatures-Single Flow Model equations in the two tanks. The governing equations for this model are given below:

$$
\begin{aligned}
& I_{1}=\frac{d W_{1}}{d t}=P_{s t}-P_{p t}-\Delta P f_{1}-\Delta P g_{1} \\
& I_{2}=\frac{d W_{2}}{d t}=P_{p t}-P_{s t}+\Delta P_{p d}-\Delta P_{f 2}-\Delta P_{g 2} \\
& (\rho A)_{s t} \frac{d L_{s t}}{d t}=W_{2}-W_{1} \\
& (\rho A)_{p t} \frac{d L_{p t}}{d t}=W_{1}-W_{2} \\
& \Delta P_{g}=g \sum(\rho \Delta Z)
\end{aligned}
$$

Predictions of the natural convection flows made with the two flow model are also given in Fig..9. for comparison with test and single flow models. It can be seen that the two flow model shows considerable improvement over single flow model, but experimental stagnation time is much larger compared to predictions. This then suggests some sort of thermal stratification effects in the piping at low natural convection flows, the prediction of which would need two or three dimensional analysis.

In natural convection flow estimation, the temperature and flow distribution are closely and strongly coupled. The temperature evolutions in IHX and SG observed in the test predicted by the two flow models is given in Fig.13. It can be noted that the two flow model is superior to the single flow model.

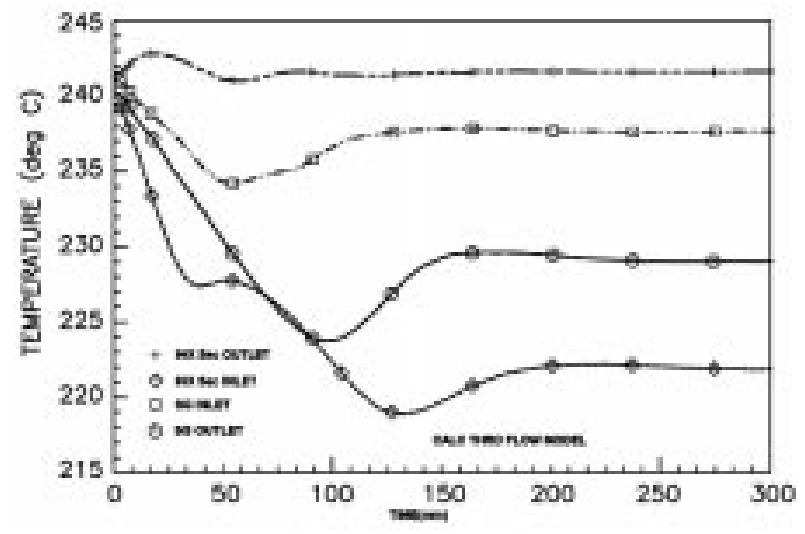

Fig. 13. Evolution of IHX and SG Temperatures-Two Flow Model 


\section{CONCLUSIONS}

Natural convection test in the secondary circuit of FBTR has shown that the layout of the circuit is conducive to natural convection for as low a power as $180 \mathrm{KW}$. One dimensional model can be used with advantage to assess the evolution of natural convection with reasonable accuracy and is sufficient for overall plant safety studies. It must be noted that better accuracy is obtainable by modeling the various capacities, which have an important role in the value of natural convection flows. Under natural convection flows and temperature distributions are highly coupled. Friction factor in pipes and components has an important influence and hence experimental data must be available on these for better predictions. For getting a better insight into the whole process, one has to resort to multi dimensional approaches, but these would be computationally more demanding.

\section{REFERENCES}

[1] Clauzon.P.P, Carlon.P.,Meyer-Heine.A.,Penet.F.,1976, Safety conclusions from startup tests and from core behaviour of PHENIX, Proc. Int. Meet. On Fast Reactor Safety and related Physics, Chicago, CONF-761001, P61.
[2] Favet et.al.,1990,Natural convection tests in SPX-1,Int.Fast Reactor Safety Meeting, Snowbird,p279.

[3] Gregory.C.V.et.al,1979, Natural convection studies in support of Dounreay PFR, ANS/ENS Int. conf. on Fast Reactor Safety Technology, .

[4] Singer.R.M.et.al.,1985, Decay heat removal and dynamic plant testing at EBR II, Second Specialists meeting in LMFBRs, Brookehaven Nat. Lab..

[5] Yoshino.E., 1985, Activities on Natural circulation tests in Joyo, ibid.

[6] Essig.C.,1985, Dynamic behaviour of RAPSODIE in exceptional transient experiments,Int. Topical Meeting on Fast Reactor Safety, Knoxville.

[7] Planchon,H.P., Goldden,G.H., Sackjett.J.I.,1987, Demonstration of passive safety features in EBR II, CONF-870415-3.

[8] Vaidyanathan.G.,Kasinathan.N.,Velusamy.K.,2010,Dyn amic model of Fast Breeder Test Reactor, Annals of Nuclear Energy, 37,,p450.

[9] Chang, Won-pyo, Kwon. Young-Min, Lee. Yong-Bum, Hahn. Dohee, 2002,Model Development for analysis of the Korean advanced liquid metal reactor, Nuclear Engineering and Design, V217, p83. 